\title{
RESISTIVITY RECOVERY OF THIN SPUTTERED ALUMINIUM FILMS
}

\author{
C. R. TELLIER and A. J. TOSSER $\dagger$ \\ Université de Haute-Normandie, Laboratoire d'Electronique et d'Automatique, \\ U.E.R. des Sciences \& Techniques B.P. 4006, 76077 Le Havre Cedex, France.
}

(Received 5 May, 1976)

\begin{abstract}
Aluminium films were r.f. sputtered onto vycor slides. Annealing induces a decrease of resistivity at temperatures between $300 \mathrm{~K}$ and $414 \mathrm{~K}$. Isothermal resistance recovery occurs with a constant rate depending on the annealing temperature; the activation energy increases from $0.3 \mathrm{eV}$ to $0.4 \mathrm{eV}$ for increasing thickness. The resistivity recovery is attributed to a surface reordering phenomenon, which is in good agreement with the Mayadas-Shatzkes conduction occuring in these polycrystalline films, with a thickness independent mean grain diameter. Reflections on grain boundaries are independent of ageing, whereas the reflection coefficient on the upper surface is increased.
\end{abstract}

\section{INTRODUCTION}

We have previously shown that an ageing process results in an increase in stability and reproducibility of the electrical characteristics of thin zinc d.c. sputtered films, ${ }^{1}$ this is also found for aluminium (Al) films deposited by r.f. sputtering. ${ }^{2}$

The variation of sheet resistance of sputtered zinc films with thickness has been studied and has given evidence of the existence of two layers within the metallic film. ${ }^{3}$ The lower layer has a constant thickness equal to the first critical thickness defined by Laville-Saint-Martin; ${ }^{4}$ the film is continuous above this thickness and shows island structure below. The upper layer has a delocalized growth, as theoretically predicted, ${ }^{4}$ and is homogeneous.

The surface of this layer becomes smooth for a thickness of approximately $1000 \AA$ which is the second critical thickness as predicted by the nucleation-growth. ${ }^{4}$

Electronic conduction in the second layer is related to a Mayadas-Shatzkes mode ${ }^{5}$ with a constant grain size: the reflections of electrons essentially occur at grain boundaries but slight reflections at the top surface also occur; these are modified by ageing since this process induces a recording of the top surface. ${ }^{6,7,8}$

Similar phenomena occur in Al. sputtered films, ${ }^{2}$ and a weak recovery of resistivity (less than $20 \%$ ) is also induced by ageing. ${ }^{2}$

$\dagger$ Actually with Université de Nancy. 1, Laboratoire d'Électronique, case officielle 140,54037 Nancy Cedex, France.
Further experiments have been performed to determine the nature of the resistance recovery; they are reported in this paper.

\section{EXPERIMENTAL}

An ultimate pressure of $2.10^{-6}$ Torr was achieved in the vacuum chamber using a primary mechanical pump and an oil diffusion pump with a water cooled baffle. The aluminium films were r.f. sputtered from a high purity $(99,999 \%)$ target in an atmosphere of $\mathrm{U}$. grade argon $\left(4.10^{-3}\right.$ Torr) onto vycor slides. The distance between the target and the substrate was $60 \mathrm{~mm}$, and an out-of-contact mask was used to define the area of the aluminium films $(9 \mathrm{~mm} \times 56 \mathrm{~mm})$.

The substrate was annealed at $573 \mathrm{~K}$ for 18 hours in high vacuum and then cooled to $293 \mathrm{~K}$ before the sputtering process began. Initially, the substrate was shielded for 10 minutes to enable the target to be cleaned by presputtering.

The substrate was laid in a copper block; a programmed and regulated furnace ${ }^{9}$ was used to anneal the aluminum films "in-situ" at constant temperature (in the $293 \mathrm{~K}$ to $414 \mathrm{~K}$ range) for various times.

The anneal at $414 \mathrm{~K}$ was performed at a pressure of $4.10^{-6}$ Torr for several hours, until the electrical resistance of the films became constant and reversible variations of the stabilized resistance with temperature were then observed. To calculate the 
values of the resistance, measurements of d.c. current were made using an opposition method.

\section{RESISTIVITY MEASUREMENTS}

\subsection{Intermediate Recoveries}

If the ageing process is stopped at an arbitrary temperature and time and the temperature then lowered in increments during a given time, linear plots of $R$ versus $T$ are obtained, and the slope $\delta \mathrm{R} / \delta \mathrm{T}$ does not depend on the ageing temperature nor on the ageing time, except for thinner films.

This shows that a defect introduced resistivity is temperature independent and is additive to the temperature-dependent resistivity.

\subsection{Isothermal Recovery}

The isothermal resistance recovery $\Delta R(t)$ is defined as the difference between the measured resistance $\mathrm{R}(\mathrm{t})$ at temperature TK and the resistance after

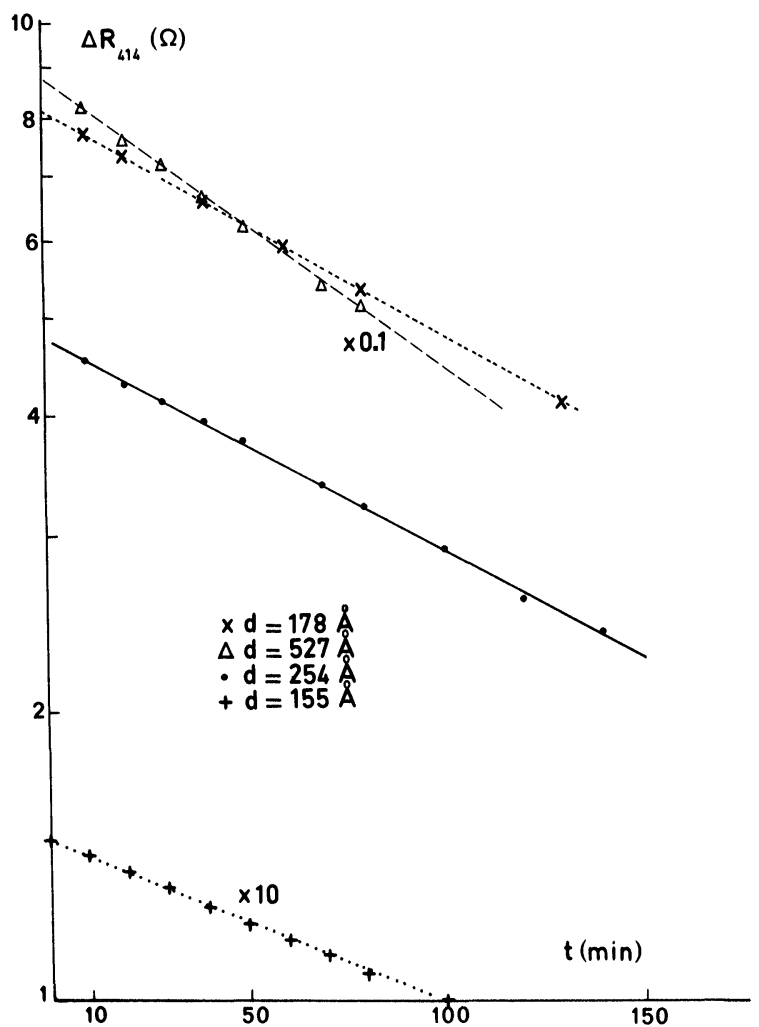

FIGURE 1 Isothermal annealing at $414 \mathrm{~K}$ : Resistance Recovery $\Delta R$ versus the annealing time $t$. annealing at $414 \mathrm{~K}$; $t$ being the annealing time. Variations of $\log _{\epsilon} \Delta R(t)$ with $t$, at temperature $414 \mathrm{~K}$, are reported in Figure 1, for different values of the film thickness.

The resistance recovery can often be written as a rate equation ${ }^{10,11}$

$$
\mathrm{d} \Delta \mathrm{R} / \mathrm{dt}=-\mathrm{K}(\Delta \mathrm{R})^{\mathrm{m}}
$$

where $m$ is the order of the reaction.

From figure 1 it can be seen that $d \log \Delta R(t) / d t$ is a constant for a particular film which may be expressed as:

$$
\mathrm{d} \log _{\epsilon} \Delta \mathrm{R}(\mathrm{t}) / \mathrm{dt}=-\mathrm{C}_{1}
$$

Therefore

$$
\log _{\epsilon} \Delta R(t)=-C_{1} t+C_{2}
$$

or

$$
\Delta R(t)=C \exp \left(-C_{1} t\right)
$$

where

$$
\mathrm{C}=\operatorname{expC_{2}}
$$

Thus, from equation (3)

$$
\frac{\mathrm{d} \Delta \mathrm{R}(\mathrm{t})}{\mathrm{dt}}=-\mathrm{C}_{1} \cdot \mathrm{C} \exp -\mathrm{C}_{1} \mathrm{t}
$$

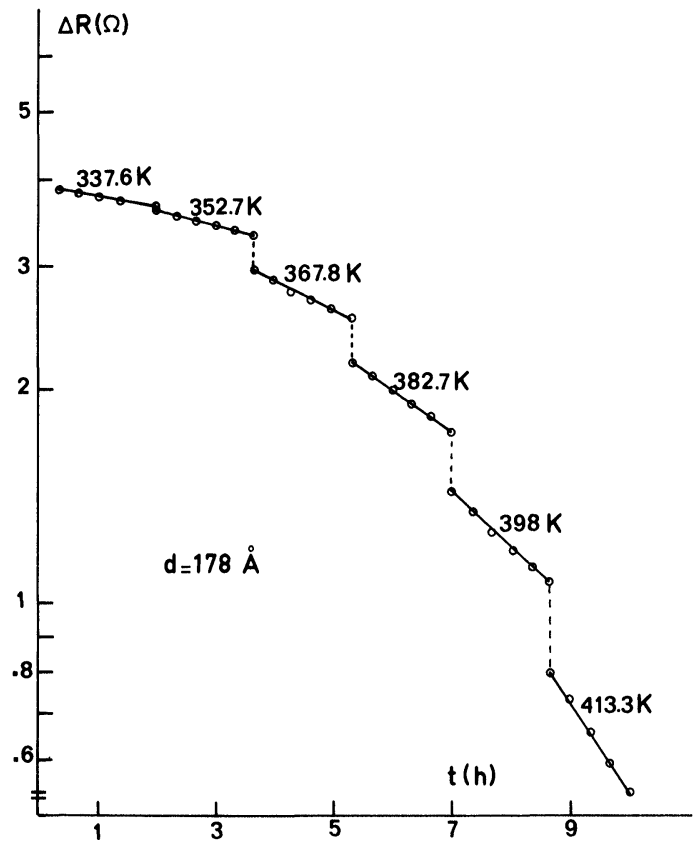

FIGURE 2 Isothermal annealing of a $178 \AA$ thick $\mathrm{A} 1$. film at various temperatures $T$ : Resistance recovery $\Delta R$ versus the annealing time $t$. 
or

$$
\frac{\mathrm{d} \Delta \mathrm{R}(\mathrm{t})}{\mathrm{dt}}=-\mathrm{C}_{1} \Delta \mathrm{R}(\mathrm{t})
$$

Comparison of Eq. (1) and (4) shows that $m=1$; the isothermal resistance recovery at $414 \mathrm{~K}$ is a first order reaction.

The variation of $\log _{\epsilon} \Delta(T)$ with annealing time at TK is shown in Figure 2, for different values of the temperature $\mathrm{T}$ and for an initial resistance of $70 \Omega$. Linear laws are obtained in temperature ranges from $305 \mathrm{~K}$ to $414 \mathrm{~K}$; the slope depends on the annealing temperature and on the film thickness.

For a given thickness, $\log _{\epsilon} \mathrm{K}$ is a linear function of $\mathrm{T}^{-1}$, as shown in Figure 3; that gives ${ }^{10}$ :

$$
\mathrm{K}=\mathrm{K}_{\mathbf{0}} \exp \left(-\mathrm{Q} \cdot \mathrm{k}^{-1} \mathrm{~T}^{-1}\right)
$$

where $\mathrm{k}$ is Boltzman's constant and $\mathrm{Q}$ is the activation energy in $\mathrm{eV}$. The activation energy $\mathrm{Q}$ varies with the film thickness $d$ (Figure 4) and increases from $0.32 \mathrm{eV}$ to $0.42 \mathrm{eV}$ with increasing thickness $150 \AA$ to $600 \AA$ in good agreement with the results of other authors. $12,13,14$

\subsection{Isochronal Recovery}

The isochronal resistance recovery $\Delta R(T)$ is defined as the difference between the measured resistance $R_{t}(T)$, after successively annealing for $2 \mathrm{~h} 30 \mathrm{~min}$ at various temperatures and the resistance measured at TK after annealing at $414 \mathrm{~K}$.

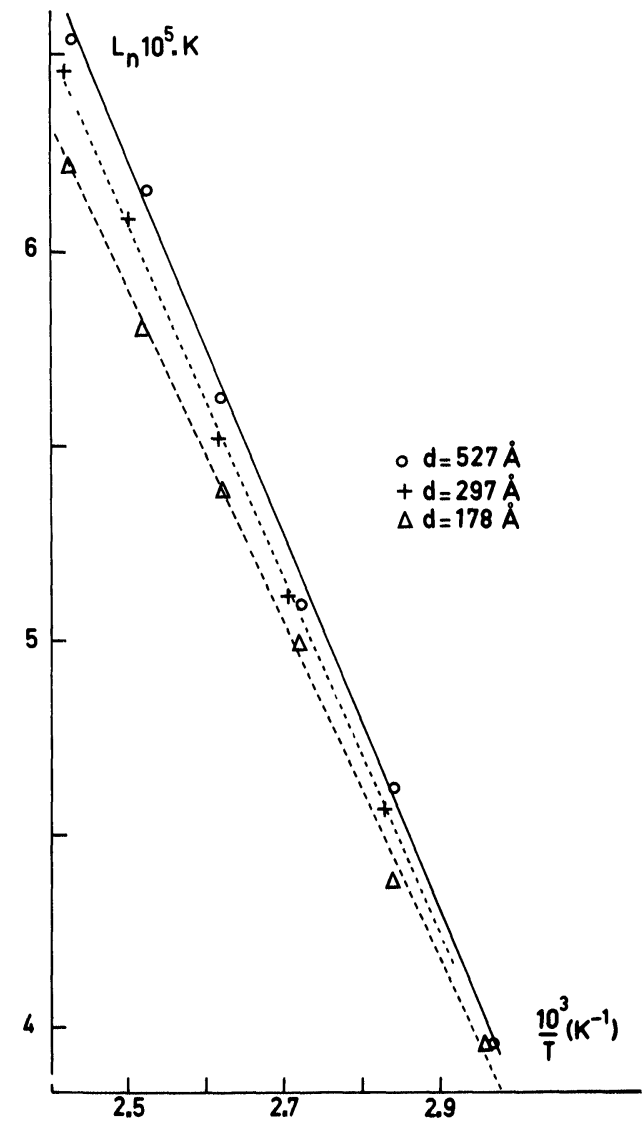

FIGURE 3 Ln $\mathrm{K}$ versus the reciprocal temperature $\mathrm{T}^{-1}$ for Al. films of various thicknesses.

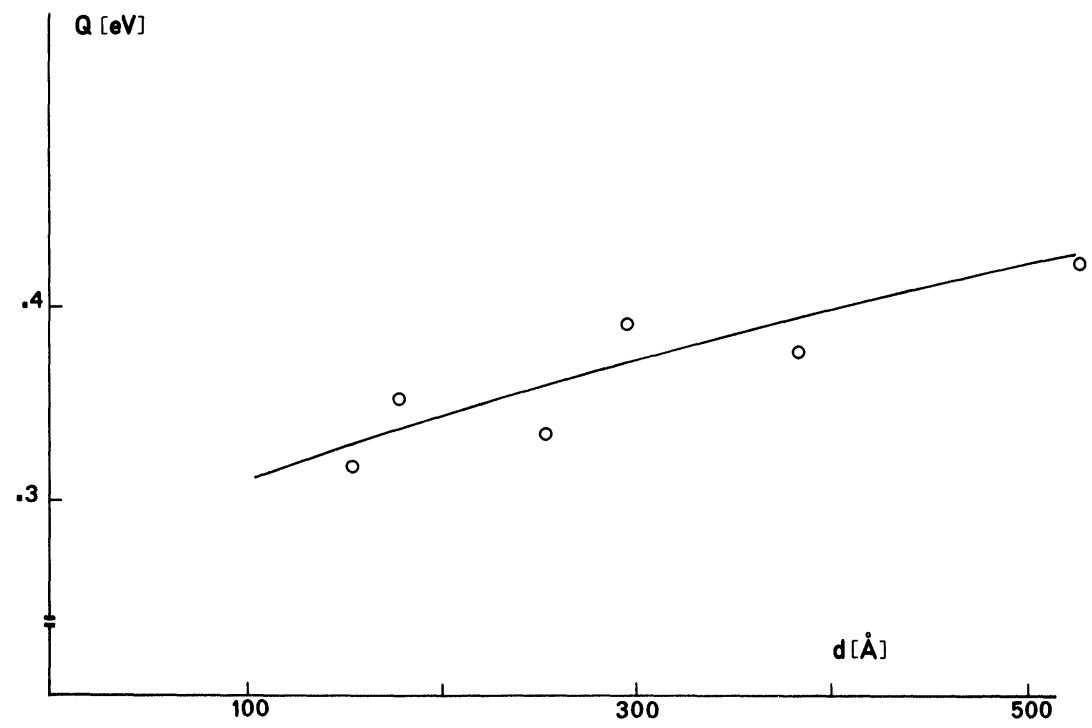

FIGURE 4 Activation energy $Q$ versus the thickness $d$ of annealed Al. films. 


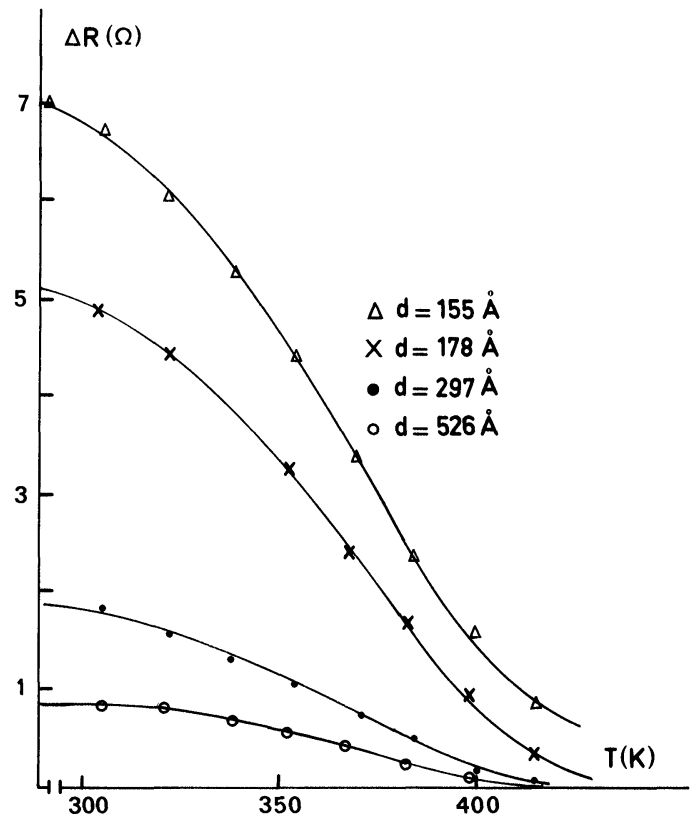

FIGURE 5 Isochronal annealing for $2 \mathrm{~h} 30 \mathrm{~min}$ of $\mathrm{Al}$. films of various thicknesses: Resistance recovery $\Delta R$ versus the annealing temperature $\mathrm{T}$.

The $\Delta R(T), T$ curves have the usual features (Figure 5). It is observed that ageing is significant at lower temperatures for the thinner films (above $300 \mathrm{~K}$ for $150 \AA$; above $340 \mathrm{~K}$ for $450 \AA$ ).

\section{DISCUSSION}

It has been shown that the maximum values of the decay energy of lattice distortion spectrum of evaporated films is higher than $1.2 \mathrm{eV} ; \mathbf{1 5 , 1 6 , 1 8}$ since the nucleated-grown films give a lower concentration of defects ${ }^{4}$ an activation energy higher than $1.2 \mathrm{eV}$ should be obtained. It is inconsistent with the measured activation energy of these nucleated-grown films which is far lower. For this reason Vand's model $^{19}$ and others work which involve activation energies greater than $1 \mathrm{eV}$ can be eliminated in favour of the surface diffusion model, which agrees with some electrical properties.

It has effectively been previously shown ${ }^{2}$ that the d.c. conduction in the second layer of these sputtered films occurs according to the Mayadas-Shatzkes ${ }^{5}$ model, with a constant grain size (about $114 \AA$ ). The linearized expressions of Mola and Heras ${ }^{20}$ have allowed the calculation of the parameter:

$$
\alpha=\left(1_{0} / \mathrm{D}\right)[R /(1-R)]
$$

where $1_{0}$ is the background electron mean free path, $\mathrm{D}$ the mean grain diameter and $R$ the electronic reflection parameter at grain boundaries. It gives ${ }^{21}$

$$
\begin{aligned}
& \alpha \approx 3.02 \text { before ageing } \\
& \alpha \approx 2.94 \text { after ageing }
\end{aligned}
$$

That indicates the slight effect of ageing on grains. From the linearization coefficients of Mola and Heras $^{20}$ approximate values of the specular reflection factor on the top surfaces $p$ have been calculated i.e. ${ }^{2}$

$$
\begin{aligned}
& p \approx 0.02 \text { before ageing } \\
& p \approx 0.41 \text { after ageing }
\end{aligned}
$$$$
\text { and }
$$

If the interfaces are different, $p$ is the mean reflection factor according to Juretschke. ${ }^{22}$

Since the interface between the first layer (of critical thickness) and the second layer is not modified by ageing ${ }^{2}$ (except for thinner films), the improvement of $p$ is attributed to top surface reordering.

Adda and Philibert ${ }^{23}$ and Quére ${ }^{24}$ have compared the activation energies of $\mathrm{Al}, \mathrm{Cu}, \mathrm{Ag}, \mathrm{Ni}$ and $\mathrm{Pt}$ when self-diffusion, surface and grain-boundaries diffusion occur. The surface activation energy is generally four or five times lower than the self diffusion energy; in aluminium the bulk activation energy is $1.4 \mathrm{eV}^{24}$ The measured values of the activation energy are thus quite consistent with a surface process ${ }^{14}$.

This assumption agrees with the increase of the activation energy when the thickness increases from $150 \AA$ to $600 \AA$. The nucleation-growth model indeed indicates that between the first and the second critical zone ${ }^{4}$ a progressive improvement of the smoothness of the upper surface occurs which is associated with better ordering and induces a higher value of the activation energy. We may deduce that the irreversible changes of resistivity induced by ageing are slight, since the phenomena are superficial. This is in good agreement with the observed variations of the ratio $R_{s} / R_{o}$ with $R_{o}$ and $R_{s}$ being the values of the resistance, respectively before and after annealing at $414 \mathrm{~K}$ (Figure 6).

Figures 4 and 6 show that different laws are valid for thinner films. It has been observed that $90 \AA$ thick films show an irreversible increase in their electrical resistance immediately after deposition, which may be due to an island type of structure, as previously proposed by other authors. ${ }^{25,26,34}$

The fact that the resistance of a $130 \AA$ thick film decreases after deposition to a stable value indicates an ordering of the film surface. $7,8,27,28,29$ 


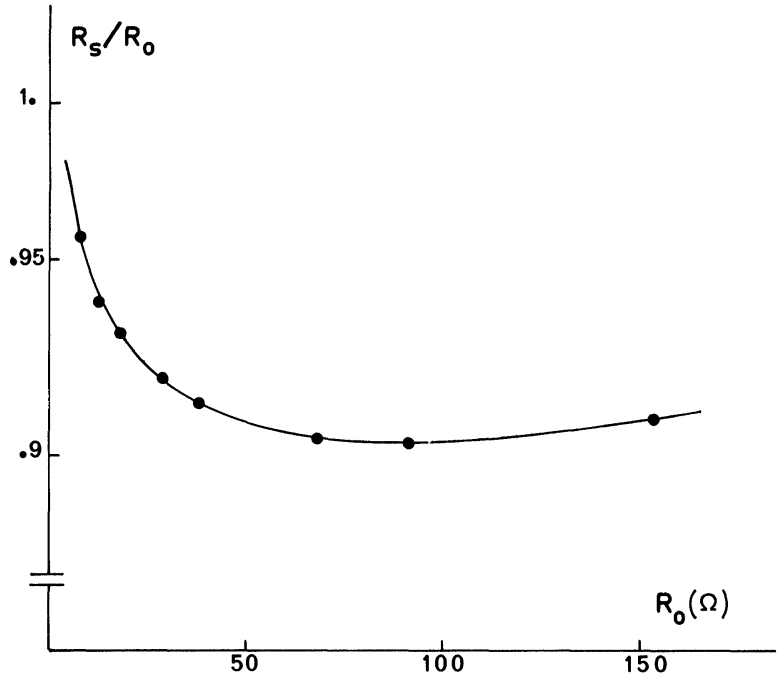

FIGURE 6 Variations of the ratio $R_{S} / R_{O}$ of the resistance $R_{S}$ and $R_{O}$ of annealed and un-annealed films with $R_{0}$.

We thus assume that the first critical thickness for which a continuous film structure is found is approximately $110 \AA$, in agreement with the results of other authors. $4,12,26,30,31,32,33$

The low values of the activation energy $(<0.2 \mathrm{eV})$ for thinner films are related to the high disordering of films ${ }^{11}$ of thicknesses of approximately the critical value.

\section{CONCLUSION}

The observed resistivity recoveries of thin r.f. sputtered aluminium films are consistent with the nucleation-growth model of sputtered films since a bulk phenomenon with a low activation energy occurs in the first critical layer, whereas a surface reordering phenomenon occurs on the surface of the second layer, with an activation energy of about $0.4 \mathrm{e} . \mathrm{V}$.

\section{REFERENCES}

1. A. Tosser and G. Fleury, Thin Solid Films, 15 (1973) 259.

2. C. Tellier and A. Tosser, M-S conduction in nucleated- grown r.f. sputtered films of aluminium, Thin Solid Films (1976) (in press).

3. C. Tellier and A. Tosser, Nucleation-growth of thin sputtered zinc films, Thin Solid Films, 35 (1976) 65-74.

4. B. Laville Saint-Martin, Thin Solid Films, 6 (1970) 359

5. A. F. Mayadas and M. Shatzkes, Phys. Rev. B, 1 (1970) 1382.

6. J. P. Chauvineau, P. Croce, G. Devant and M. F. Verhaeghe, J. Vac. Sci. \& Technol., 6 (1969) 776.

7. T. T. Sheng, R. B. Marcus, F. Alexander and W. A. Reed, Thin Solid Films, 14 (1972) 289.

8. A. K. Pal, Paramita Sen and A. K. Barua, Thin Solid Films, 25 (1975) 925.

9. A. Piel, G. Fleury and A. Tosser, Measures, 38 (1973) 37.

10. G. J. Van Gurp, J. Appl. Phys., 46 (1975) 1922.

11. R. L. Longini and S. R. Pansino, J. Appl. Phys., 40 (1969) 2653.

12. M. Adamov, B. Perovic and T. Nenadovic, Thin Solid Films, 24 (1974) 89.

13. A. P. Dorey and J. Knight, Thin Solid Films, 4 (1969) 445.

14. R. E. Hummel and H. J. Geier, Thin Solid Fïlms, 25 (1975) 335 .

15. H. Toyota, N. Nagashima, J. Phys. Soc. Japan, 14 (1959) 274

16. P. G. Wilkinson, J. Appl. Phys., 22 (1951) 419.

17. V. V. Sham and Y. G. Naik, Ind. J. Pure Appl. Phys., 3 (1965) 20.

18. V. Damodara Das and M. S. Jagadeesh, Thin Solid Films, 24 (1974) 203.

19. V. Vand, Proc. Phys. Soc., 55 (1943) 222.

20. E. E. Mola, J. M. Heras, Thin Solid Films, 18 (1973) 137.

21. C. Tellier, Project de thèse de Doctorat de 3e cycle, Université de Rouen (1976).

22. H. Juretschke, J. Appl. Phys., 37 (1966) 435.

23. Y. Adda and J. Philibert, La diffusion dans les solides, Tome II, Presses Universitaires de France (Paris) (1966).

24. Y. Quéré, Défauts ponctuels dans les métaux, Masson \& Cie (Paris) 1967.

25. S. Mohan and P. Jayarama, Phys. Stat. Sol. A., 15 (1973) $\mathrm{K} 1$.

26. B. Singh and N. A. Surplice, Thin Solid Films, 10 (1972) 243.

27. M. S. P. Lucas, Appl. Phys. Lett., 4 (1964) 73.

28. J. P. Chauvineau and C. Pariset, Surf. Sci., 36 (1973) 155.

29. T. J. Coutts, Thin Solid Films 7 (1971) 77.

30. K. L. Chopra, L. C. Bobb and M. H. Francombe, J. Appl. Phys., 34 (1963) 1699.

31. P. Michon, Thin Solid Films, 16 (1973) 335.

32. S. C. Jain and R. Chander, J. Appl. Phys., 39 (1968) 5343.

33. R. Suri, A. P. Thakoor and K. L. Chopra, J. Appl. Phys., 46 (1975) 2574.

34. J. Le Bas, C.R. Acad. Sc. Paris, 273 (1971) 1044. 

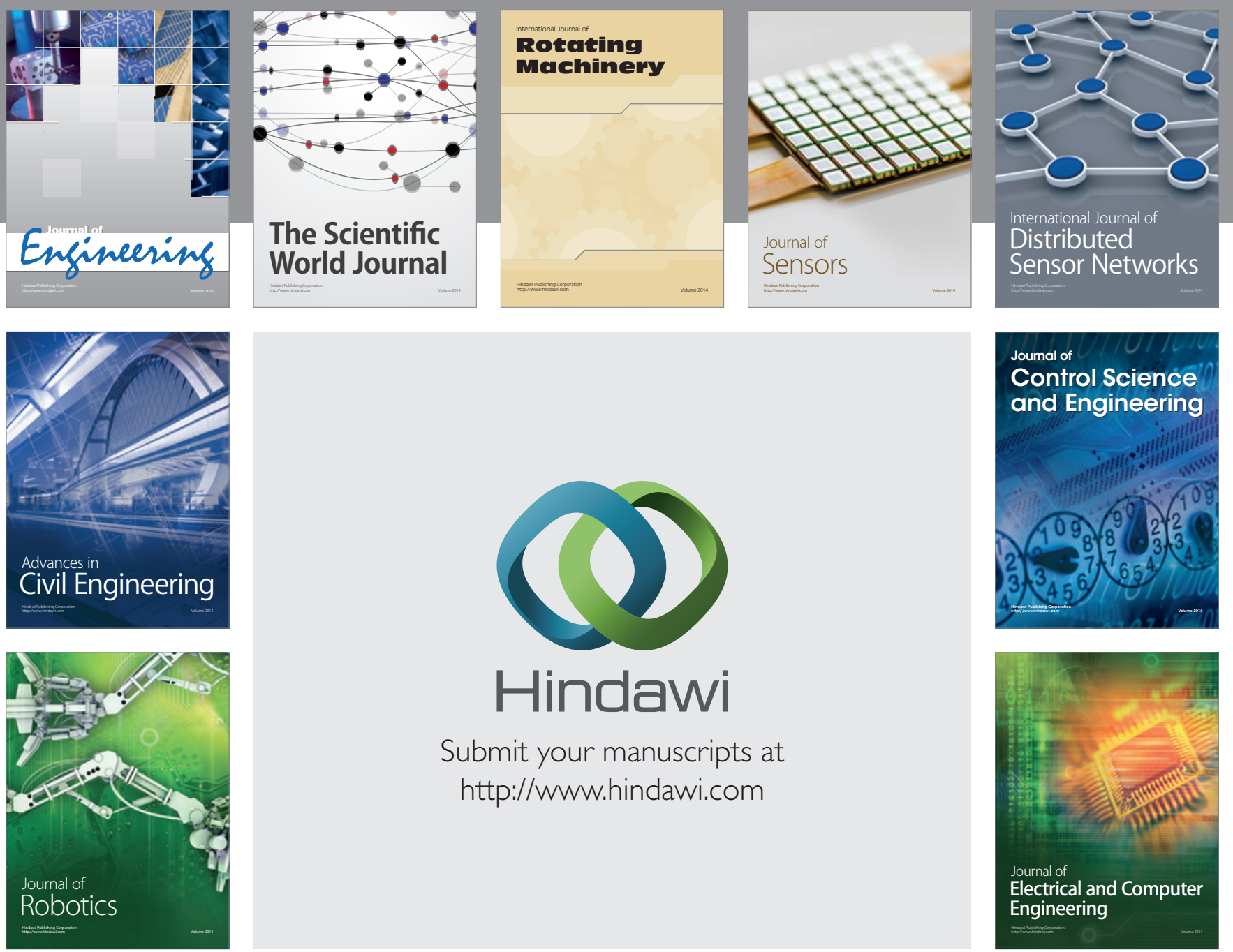

Submit your manuscripts at

http://www.hindawi.com
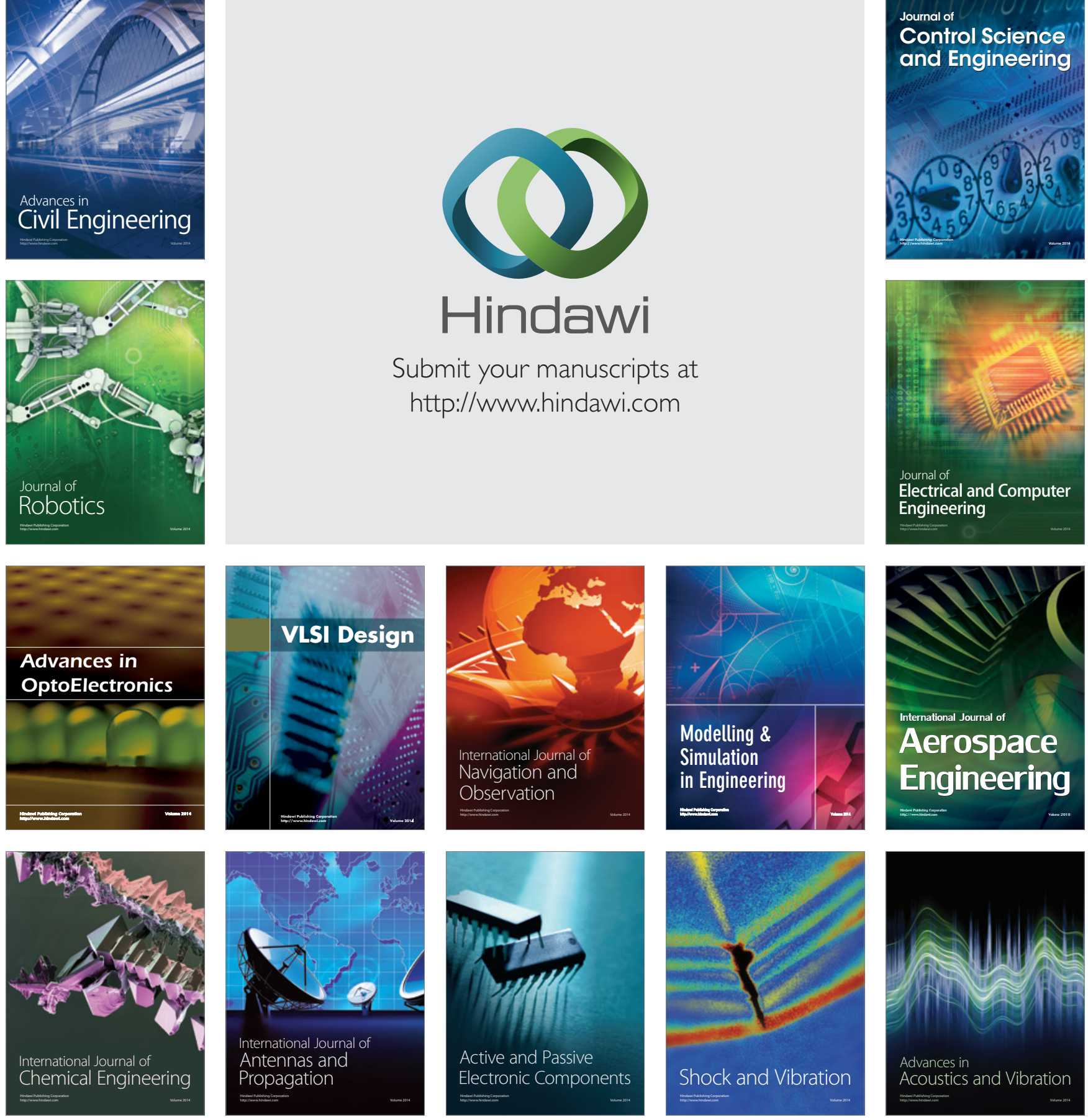